\title{
1
}

\section{Involving managers with information technology-bridging the culture gap}

\author{
G.L. Altmann \\ Deakin University, \\ Geelong, Victoria, 3217, Australia \\ telephone+615227 1034, fax +6152272151 \\ emailaltmann@deakin.edu.au
}

\begin{abstract}
Finding better ways of involving business managers in learning about information systems (IS) and information technology (IT) is a continuing challenge for educators. Contemporary management education has typically addressed this problem by primarily focusing on giving the manager a better appreciation of the technologies and outlining the technical skills employed by IS professionals, but this approach neglects the critical needs of management by paying too much attention to inappropriate issues. As we move towards the next millennium, the best managers will be those who can look beyond the technology to see business solutions and can see how technology can be used to deliver business opportunities.

An appropriate educational strategy must concentrate on enabling the business manager to take an active role in directing and managing the uses to which IS/IT is put within the organisation. This paper outlines an approach that is used to clearly focus on the manager's role in respect to IS/IT, and sets tasks within the manager's own work situation. Soft systems methodology is used to involve participants in tasks associated with the planning and analysis of business information needs. The focus of the approach is on learning about and developing the existing system, and on discovering innovative ways of carrying out new system activities. Managers are put into the role of a consulting analyst to prepare a critique of their organisation's current IS/IT management practices and some simple prescriptions are proposed for creating a positive organisational IS/IT culture.
\end{abstract}

\section{Keywords}

Management education, action learning, soft systems methodology, information systems culture 


\section{INTRODUCTION}

The power of modern information systems and information technology (IS/IT) offers new opportunities to rethink, at the broadest levels, existing business strategies, approaches and practices. Over the past decade, IT has opened up new business opportunities, led to the development of new strategic IS and challenged all managers and users of IS/IT to devise new ways to make better use of information. Yet this era which began with much confidence and optimism is now suffering under a legacy of systems that are increasingly failing to meet business needs, and lasting fixes are proving costly and difficult to implement.

General management is experiencing a crisis of confidence in their IS functions and in the chief information systems officers who lead them (Earl and Feeney, 1994:11). The concern for chief executive officers is that they are confronting a situation that is seemingly out of control. They are asking, 'What is the best way to rein in these problems and effectively assess IS performance? Further, how can we be certain that IS is adequately adding value to the organisational bottom line?'

On the other hand, IS executives and professionals who are responsible for creating, managing and maintaining the organisation's systems are worried about the preparedness of general managers to cope with the growth in new technologies and systems. They see IT having a polarising effect on general managers; it either bedazzles or frightens them (Davenport, 1994:119). Information technology has become the 'invisible factor' (Daniels, 1994:141) - a business resource that is here already, yet existing with a management culture that is struggling to understand its complexities and potential.

In this paper we will examine these perplexing issues and look at how we can form the genesis of a solution by creating a better working relationship between general management and IS professionals. We will also examine whether general managers are being adequately equipped through traditional management information systems (MIS) education and IS training programs to face the challenges involved in managing businesses which are increasingly reliant on IS/IT for growth and survival.

\section{THE CHANGING ROLE OF THE GENERAL MANAGER}

One of the unique and distinctive features of management is that it is a vocation that creates and defines its own roles and work tasks (Linstead, 1990:63). Preparing managers to act decisively and with confidence is a critical prerequisite to enabling a sound response to any situation. For senior management, active questioning of IS/IT performance and involvement in IS/IT management has become a business necessity. The role of the general manager has widened to take in an area that was once the sole province of IS professionals. IS/IT areas in which proactive managers are now routinely involved include:

- Finding ways to use IT more competitively and creatively in the business.

- Critiquing the capability of systems to meet management objectives.

- Assessing the feasibility of investing in new technologies.

- Ensuring that IS/IT strategic planning is linked to business strategies.

- Managing information systems project teams.

- Chairing IS/IT steering committees and policy boards. 
In the same way, IT managers who were once merely thought of as 'technology gatekeepers' are learning to take on new business roles. Today, the primary responsibilities of IT managers must include (Sprague and McNurlin, 1993: 38):

- Understanding the business, particularly the markets in which the firm sells its products and services.

- Establishing credibility of the systems department, thereby increasing the confidence of executive management in ideas presented by systems management.

- Increasing the technological maturity of the firm, making it easier to take advantage of computer and telecommunications applications throughout the firm.

- Creating a vision of the future and selling it, setting a goal for the use of information technology within the organisation and selling that goal to others.

- Implementing an IS architecture that will support that vision and the company into the future.

It was once thought that if general managers could be encouraged to make more use of computers and IT in their daily work that this would translate into changed ways of doing business. Unfortunately, a survey of 1500 British managers indicates that general managers have been largely 'isolated, short-sighted and unimaginative' in their use of IT (Bird, 1992:101). We might ask, 'How can managers be best involved in learning about the key aspects of IS/IT which are essential to managing the organisation?'

\section{LEARNING BY DOING}

For most managers learning is taken to mean 'learning by doing'. This type of learning is also known as 'action learning' (Revans, 1980) because it requires the learner to participate in processes that lead to real changes. Action learning allows the learner to control the learningstage and influence the activities taking place around them. When this type of interaction fails to occur, then the learner is merely experiencing or enduring the learning process. Avison (1991:66) argues that it is not suggested that conventional learning methods are invalid, but the very nature of IS suggest that the best way to learn is through implementing action learning programs. That is, we want to be able to draw on the experience of the learner and at the same time actively embrace them in action learning activities. Pye (1994:163) has described this idea of action learning as a process of reflection by which the learner generally looks back over an experience and makes a particular sense of it, from this process they can say that they have drawn some lessons and may consequently change their future behaviour.

One of the difficulties of involving managers in action learning programs is in overcoming the widely-held belief that such learning is really no more than an application of commonsense. The following allegory illustrates the dilemma of adhering to this view. Hayakawa (1991 quoted in Pye, 1994:164) raises:

'the captivating idea that 'common-sense' is that which tells us that the world is flat. It is a wonderful illustration because this very simple idea embraces a very complex inconsistency of human behaviour. That is, we can, and indeed often must, see something in quite opposing ways in order to make sense of it. ... We 'know' that the world is round, but to all intents and daily purposes, we also know that it is relatively speaking flat. And most people would probably claim that they are not being inconsistent in combining such contrasting views. 
... It is merely an assumed simplification by which we make sense of our worlds; the world is both round and flat.'

A parallel to this idea in the IS/IT world is being able to draw a distinction between thinking and working in the conceptual 'systems world' and the practical 'real world'. Working exclusively in either domain will not provide all the answers, one must be able to move freely between both worlds. What is important is being able to move outside ones own viewpoint of a situation and being able to review activities and functions from a different perspective. Using this approach we want to put our learners into the position of IS/IT 'consultants' to their own organisations. This consultancy approach can be the central point in developing an IS/IT course for general managers.

\section{DESIGNING AN EDUCATIONAL STRATEGY}

Deakin University's Master of Business Administration (MBA) program was established in 1981 and is today widely acknowledged as one of the world's first distance-learning MBA programs. Participants in the program are senior and middle managers working in a wide variety of Australian and international organisations. They typically have backgrounds in fields such as accountancy, administration, manufacturing, mining and engineering. Nearly $8 \%$ of participants work in the IS industry, with over half of these IS professionals working in senior management positions.

MBA program participants are located hundreds and often thousands of kilometres from the University. So to achieve desired levels of student interaction and support, the University has developed an electronic communication system known as Deakin Interchange. Deakin Interchange allows students to enjoy the feeling of 'being on-campus' without leaving their homes or places of work. They can use the system to contact their lecturers and fellow students, participate in group meetings, and have access to all library and IT services. This interaction can be initiated 24 hours a day, every day of the year.

MBA participants are required to complete a compulsory semester course on Information Systems Management. This course provides participant managers with a broad base of IS/IT knowledge and develops their management skills and competencies through a set of related activities and assignments. Some of the IS/IT areas covered in the course include:

- Defining the strategic role of IS.

- IS planning.

- Building an information vision and IT architecture.

- Managing information resources.

- Managing system development.

- Project risk management.

- Promoting partnerships between IS and business management.

- Managing change.

Closely following the philosophy of learning by doing, participants in the Deakin MBA are required to directly apply new skills and knowledge as a key part of the learning process. To this end, assignments are set in the workplace and are centred around in-text activities which build to become major assessable tasks. Over the course of a thirteen week semester, students are required to draw on their experience and involvement with IS/IT to complete two major assignments. 
The first of these assignments provides managers with an opportunity to better understand the key IS needs of their organisations through a 'soft' analysis of each business. This exercise is achieved by using soft systems methodology (SSM) initially developed by Checkland (1981). SSM is strongly action oriented and it encourages the development and resolution of multiple viewpoints of system purpose and functions. The approach involves an iterative process of thinking about problem situations, developing 'rich pictures' and 'root definitions', conceptual modelling of relevant human activity systems, comparing models with the real world, and then taking action to improve the original real world situation. The conceptual models are carefully built models of purposeful activities and represent a description of what the organisation does, could, should, or intends to do.

The fact that SSM explicitly recognises and accommodates the fact that different players usually have different views about the aims, objectives, and purposes of the organisation, contributes to the potential of the approach to develop new and innovative variations to realworld problems. One of the key points that Checkland makes about SSM is that it is essentially a learning process, with the emphasis on learning about the system (both as it is and as it could be) and taking action to change and improve it based on that learning. This contrasts with traditional business analysis approaches where the focus tends to be on optimising the existing system and the procedures and processes within it.

The second of the assignments asks participants to prepare a critique of their organisation's current management practices in relation to IS/IT. Areas on which these 'analysts' are asked to comment and put forward recommendations include:

- The dependence of their organisation on IS/IT.

- The growth and maturity of IS/IT.

- Approaches used for IS/IT strategic planning and policy formulation.

- The potential for the use of new technologies across the organisation.

- How IS/IT projects are initiated and how IS/IT investments are compared.

- System development methods used.

- Factors which have contributed most to the success or failure of systems projects.

- How the effectiveness of IS/IT is generally measured.

In carrying out each activity participants are able to review their own roles and determine how business needs generally and management/user needs in particular are being met. This task crystallises the outcome of participants' reflections on the whole subject area of the MIS unit. It does this by asking students to form a detached and realistic appraisal of IS/IT management in relation to their own working environment. This approach consistently leads to recommendations for new policy and/or practices which have in many instances been accepted and implemented in participant organisations.

\section{CREATING THE RIGHT CULTURE FOR CHANGE}

Culture affects the way that we view the world, the way that we think and act, and the way that we respond to particular situations. Most of us view culture narrowly, when, in actuality, it is multidimensional and extremely broad in its influence (Skoria et al, 1995:416). Organisational culture has been defined as 'the shared philosophies, ideologies, values, assumptions, beliefs, expectations, attitudes and norms that knit an organisation together' 
(Kilmann et al, 1986:88). The key word in this definition is the word 'shared', those values that are shared, widely held and dominant are the values that create a corporate culture.

Cash (1988) has described the clash of cultures that occurred between general management and IS management in the 1980s as a perfect example of C.P. Snow's classic two-culture problem. Yet today, we are at last beginning to move away from this era. The clear message emanating from managers participating in the Deakin MBA is that many of their organisations are now getting IS/IT management right. Over the period 1990 to 1995 , we have used a number of different survey instruments to assess the extent and the effectiveness of IS/IT in participants' organisations (Altmann and Boyce, 1994).

In relation to management participation in IS/IT, the surveys indicate a changing pattern. Levels of general management participation in IS/IT in the early 1990s revolved around:

- Identifying IS/IT problems.

- Managing system user personnel.

- Broadly critiquing system capabilities.

However, today there is a greater willingness on the part of management to accept more IS/IT responsibility and become involved in strategic IS/IT areas such as:

- Identifying opportunities.

- Developing strategy.

- Generating investment options.

- Evaluating investment proposals.

- Championing projects.

- Providing IS/IT leadership.

These are areas that managers see as having a major impact on their jobs so they are seeking to directly influence IS/IT policy and direction. Those managers who perceive their organisations to be industry leaders in using IS/IT, identified some factors that distinguished their own leading organisations from other lagging organisations. Key points raised were:

- A strong senior management commitment to IS/IT.

- Close alignment of IS/IT strategy with business strategy.

- An IS group that takes the time to understand the needs of the business units.

- Users who are willing to accept more responsibility for defining their own requirements.

- The presence of champions in the business who support and promote IS/IT ideas.

- An IS group working closely with senior management.

- A strong commitment to research and development.

- An ongoing program of management and user IS/IT training.

Certainly involving managers and users in understanding and identifying their own needs is a vital element in establishing the efficacy of IS in any organisation. One trend which is emerging is outlined by Dober (1994:101). He comments, at 'many ... companies and government organisations, this need has been recognised and IS staff called business analysts or account managers are being despatched to the user areas full-time. By living and breathing users issues and problems, recognising opportunities and being part of the process, a much better understanding can be developed.' Through initiatives such as this, the culture clashes of the past will at last become yesterday's news. 


\section{CONCLUSIONS}

General managers are increasingly willing and ready to be involved in IS/IT matters within their organisations. Any reluctance to act has to a large degree been a direct result of these managers receiving little or no appropriate IS/IT education or training. This suggests a paradox between the conventional role of management to provide leadership and the apparent lack of any conscious attempt to prepare them for this role in IS/IT matters.

Management education has reached the point where it must move beyond simply introducing general managers to IS technical know-how. We must ensure that managers are aware of the strategic impact that systems can have in their organisations; beyond that they must be actively involved in developing IS strategies and managing IS resources. We are beginning to see a new breed of general managers in modern organisations: leaders who can form effective partnerships with IS management groups; leaders who understand the role of IS in building a more efficient and effective organisation; and leaders who want to make IS an integral part of business planning and strategy development. Now is the time to ensure that they are empowered to act.

\section{REFERENCES}

Altmann, G. L., \& Boyce, G. (1994) New Cooks in the Kitchen-Empowering IT Users. Proceedings of the ACS Asia Pacific Computer Conference, Gold Coast, Queensland, 1-8.

Avison, D.E. (1991) Action programmes for teaching and researching information systems. The Australian Computer Journal, 23(2), 66-72.

Bird, J. (1992) Managing Information Technology-Micro Myopia. Management Today, February, 101-102.

Cash, J.I., McFarlan, F.W., \& McKenney, J.L. (1988) Corporate Information Systems Management. (2nd ed.). Illinios: Irwin.

Checkland, P. (1981) Systems Thinking, Systems Practice. Chichester UK: John Wiley \& Sons.

Daniels, N.C. (1994) Information Technology: The Management Challenge. Wokingham, England: Addison-Wesley Publishing.

Davenport, T.H. (1994) Saving IT's Soul: Human-Centered Information Management. Harvard Business Review, March-April, 119-131.

Dober, G. (1994). Ensuring an MBA covers the IT issues. Managing Information Systems, May, 110.

Earl, M.J., \& Fenney, D.F. (1994) Is Your CIO Adding Value? Sloan Management Review, Spring, 11-20.

Hayakawa, S.I. (1991) Language in Thought and Action. (5th ed.). New York: Harcourt Brace Jovanovich.

Kilmann, R.H., Saxton, M J., \& Serpa, R. (1986) Issues in Understanding and Changing Culture. California Management Review, 28(2), 88.

Linstead, S. (1990) Beyond Competence: Management Development Using Computer-based Systems in Experiential Learning. Management Education and Development, 21, 61-74.

Pye, A. (1994) Past, Present and Possibility: An Integrative Appreciation of Learning From Experience. Management Learning, 25(1), 155-173.

Revans, R.R. (1980) Action Learning. London: Blond and Briggs. 
Skoria, R.J., Kohun, F.G., \& Wood, D.F. (1995) A Framework for Studying Culture and Decision Making. Proceedings of the International Association of Computer information Systems Conference, Toronto, Canada, 414-422.

Sprague, R.H., \& McNurlin, B.C. (1993) Information Systems Management in Practice. (3rd ed.). Englewood Cliffs, NJ: Prentice Hall.

\section{BIOGRAPHY}

Graeme Altmann, B.Com., M.Sc., C.P.A., M.A.C.S, has been a Senior Lecturer in the Faculty of Management at Deakin University since 1990. During this time he has worked with participants in the Master of Business Administration (M.B.A.) program introducing them to information systems management practices and principles. He has worked as a consultant and has held management positions in academia and business. Graeme is also an active researcher and has recently presented papers on systems thinking, IS strategic planning, software quality management and IT entrepreneurship at conferences in North America, Europe, and Southeast Asia. 